\title{
ASPECTOS MULTIDIMENSIONAIS DE VULNERABILIDADE DA PESSOA IDOSA À VIOLÊNCIA NO CONTEXTO DA PANDEMIA
}

\author{
Maria de Nazaré de Souza Ribeiro' \\ ORCID: 0000-0002-7641-1004 \\ Fátima Helena do Espírito Santo" \\ ORCID: 0000-0003-4611-5586 \\ Fernanda Farias de Castro' \\ ORCID: 0000-0003-1970-5169 \\ Camila Carlos Bezerra"' \\ ORCID: 0000-0001-5896-5604 \\ Cássia Rozária da Silva Souza' \\ ORCID: 0000-0001-9790-3713 \\ Vanusa do Nascimento ${ }^{\text {IV }}$ \\ ORCID: 0000-0003-4141-2784 \\ Cleisiane Xavier Diniz' \\ ORCID: 0000-0003-4689-6204
}

Universidade do Estado do Amazonas, Escola Superior de Ciências da Saúde. Manaus, Amazonas, Brasil.

"Universidade Federal Fluminense, Escola de Enfermagem Aurora de Afonso Costa. Niterói, Rio de Janeiro, Brasil.

'"Universidade Federal do Amazonas, Escola de Enfermagem de Manaus. Manaus, Amazonas, Brasil.

"Fundação Universidade Aberta da Terceira Idade - FUnATI. Manaus, Amazonas, Brasil.

Autor Correspondente: Maria de Nazaré de Souza Ribeiro E-mail: mnribeiro@uea.edu.br

Como citar:

Ribeiro MNS, Santo FHE, Castro FF, Bezerra CC, Souza CRS, Nascimento $V$, et al. Aspectos multidimensionais de vulnerabilidade da pessoa idosa à violência no contexto da pandemia. In: Santana RF (Org.). Enfermagem gerontologica no cuidado do idoso em tempos da COVID 19. 2.ed.rev. Brasilia, DF: Editora ABEn; 2020. p 150-156. (Serie Enfermagem e Pandemias, 2). https://doi.org/10.51234/aben.20.e02.c23

\section{INTRODUÇÃO}

Limitar o conceito de violência a uma definição fixa e simples significa deixar de compreender as singularidades que caracterizam suas diversas expressões em diferentes povos, contextos, culturas e especificidades históricas. Assim, para falar de violência na contemporaneidade é preciso enxerga-la para além das marcas deixadas visivelmente no corpo. É necessário ressaltar que o termo violência carrega consigo múltiplos significados e formas, bem como distintos níveis de visibilidade, de abstração e de designação de suas assimetrias. Ela está representada em formas físicas, objetivas, subjetivas, simbólicas, sistêmicas, coletivas, individuais, visíveis e invisíveis.

Todas essas formas coexistem em nossas vidas, em estreita proximidade e simbiose. Por esse motivo, as definições de violência, tradicionalmente vinculadas à existência de dano físico, hoje, direcionam-se para aspectos multidimensionais como, por exemplo, exclusão, humilhação e discriminação por etnia, cor, sexo, escolha sexual, idade e religião, dentre outros. Ela se expressa na relação desigual do uso do poder do mais forte sobre o mais fraco em diferentes circunstâncias e lugares, causando danos à integridade física, psicológica e usurpação de direitos.

Nesse amplo leque da violência, destaca-se aquela praticada contra a pessoa idosa, como uma das mais importantes demandas que acompanha a agenda dos temas prioritários da gerontologia e que tem acarretado adoecimento físico e psicológico, quando não resultando em incapacidades e morte.

Dentre as diversas tipologias da violência contra a pessoa idosa, destacam-se a Violência Física, identificada pelo uso da força física na tentativa de obrigar os idosos a fazerem o que não querem, chegando a ferí-los, provocando dor, incapacidade ou morte; a Violência Psicológica, que inclui agressões verbais ou gestuais com o propósito de atemorizar, depreciar, destratar e humilhar com gritos, asperezas, brutalidade e impropérios; a Violência Sexual, 
manifestada pelo ato ou jogo sexual com a pessoa idosa, visando obter excitação, relação sexual ou práticas eróticas por meio de aliciamento, violência física ou ameaças e atitudes obscenas; a Violência Financeira ou econômica, que consiste na usurpação ou exploração não consentida dos recursos financeiros e patrimoniais da pessoa idosa; a Violência Emocional e Social, que envolve o desrespeito à privacidade e aos desejos das pessoas idosas, privação de acesso a amizades e necessidades tantos sociais quanto de saúde, além do uso de palavras depreciativas que menosprezam sua identidade, dignidade e autoestima; a Violência Religiosa, descreve o desrespeito pelas diferenças e/ou crenças religiosas e restringe a liberdade da prática de crenças, ritos e outros; o Abandono, associado ao absenteísmo dos responsáveis legais (governo, instituição e família) no auxílio a uma pessoa idosa que necessite de ajuda e proteção; a Negligência, caracterizada pela omissão ou recusa de cuidados necessários à pessoas idosas por parte da família, instituição ou governo; e a Autonegligência, que é a recusa da pessoa em propiciar cuidados necessários a si mesma, colocando em risco sua saúde ${ }^{(1)}$.

No mundo, um a cada seis idosos sofrem algum tipo de violência e, no Brasil, os registros de violência contra as pessoas idosas têm aumentado a cada ano. Em 2018, foram 37.454 casos, aumento de 13\% em relação ao ano de 2017. Em 2019, cresceu para $29 \%$, com 48,5 mil recebidas pelo Disque 100 . Em $80 \%$ dos casos os denunciados são familiares. As violações mais comuns são as agressões verbais, expressadas nas atitudes de humilhação, hostilidade, xingamentos, usurpação de bens e negligências ${ }^{(2)}$.

No que se refere aos profissionais da saúde, com ênfase no enfermeiro, todos têm responsabilidades direta nas discussões sobre a temática, identificação dos sinais de violência, notificação dos casos, denuncia e prevenção. Além disso, a identificação de situações de risco, por meio da observação acurada do comportamento, gestos, semblante, entonação de voz e outras expressões não verbais da pessoa idosa, possibilitará ao profissional a identificação precoce e a intervenção adequada da violência contra a pessoa idosa ${ }^{(3)}$.

Dessa forma, queremos nesse estudo, refletir sobre alguns importantes aspectos multidimensionais da violência praticada contra a pessoa idosa, considerando diversos fatores que se mostram ainda velados no contexto de vida de muitos deles, decorrentes de processos de relações sociais, institucionais, familiares, interpessoais e de gênero, que causam danos físicos, psicológicos e morais à pessoa idosa, destacando que todos esses aspectos se tornaram ainda mais preocupantes no período da pandemia de COVID-19 quando os idosos tiveram que ser mantidos em isolamento e distanciamento social.

\section{OBJETIVO}

Refletir sobre os aspectos multidimensionais da violência praticada contra a pessoa idosa no cenário da pandemia do novo coronavírus.

\section{MÉTODO}

Trata-se de um estudo teórico-reflexivo, descritivo, construído a partir de consulta à literatura científica e de percepções das autoras sobre os aspectos multidimensionais da violência que é praticada contra a pessoa idosa no contexto da pandemia da COVID-19. Dentre as multidimensionalidades dessa violência, abordou-se os aspectos físico, cognitivo, sociodemográfico e o de relação familiar com os seguintes tópicos: Incapacidade funcional e cognitiva como fator de violência; Condições sociodemográficas geradoras de violência; e Violência doméstica durante o isolamento social.

\section{INCAPACIDADE FUNCIONAL E COGNITIVA COMO FATOR DE VIOLÊNCIA}

A violência e maus-tratos contra a pessoa idosa tem se tornado um problema de saúde pública crescente, principalmente quando se apresenta como violação de direitos fundamentais daqueles em situação de maior 
vulnerabilidade, como os idosos com comprometimento funcional e cognitivo. A capacidade funcional da pessoa idosa é definida pela habilidade em executar suas Atividades de Vida Diária ou tarefas básicas sem necessidade de auxílio. Já a capacidade cognitiva, refere-se ao desempenho mental, nas funções do sentir, compreender, pensar, raciocinar, memorizar, lembrar, formar juízos coerentes e responder a estímulos externos. Tanto a capacidade funcional quanto a capacidade cognitiva são decisivas para a preservação e manutenção da autonomia e independência da pessoa idosa.

A autonomia, que se refere à associação dessa com uma memória preservada e funcional, reside na capacidade do idoso de cuidar de si e a desempenhar atividades que propiciem ajustes psicossociais. Assim sendo, o comprometimento da capacidade cognitiva interfere na capacidade funcional da pessoa idosa e vice-versa, com repercussões na perda de independência e autonomia, que varia conforme o grau de severidade, principalmente na presença de doenças crônicas-degenerativas, interferindo na qualidade de vida do idoso(4).

Pessoas idosas com algum grau de comprometimento funcional e/ou cognitivo, aparecem nas estatísticas em maior proporção de maus-tratos, apresentando histórico de episódios recorrentes de violência derivados de relações familiares conflitantes, estresse do cuidador principal, dificuldades na execução das rotinas de cuidados, coabitação multigeracional, isolamento social, comorbidades e diminuição de sua capacidade funcional e cognitiva(4).

No Brasil, a incapacidade funcional e cognitiva tem sido associada ao aumento dos eventos relacionados à violência contra a pessoa idosa, tipificada, nesses casos, nas formas de agressão física, psicológica, medicamentosa, financeira, negligência, autonegligência e abandono. A incapacidade funcional na pessoa idosa se instala quando ela passa a depender de cuidados e assistência em tarefas básicas de vida diária como alimentar-se, vestir-se, locomover-se, procurar assistência à saúde e manter o mínimo de dependência. Nesse contexto, aparece frequentemente a negligência de cuidados, acompanhada do abandono e maior chance de institucionalização. A fragilidade física e cognitiva do idoso facilita a violência, uma vez que esse pode não ter a capacidade de se defender, seja por força física ou pela incapacidade de reconhecer atos de violência.

Tanto a incapacidade física como a cognitiva, colocam o idoso em situação de maior exposição à maus-tratos. Os idosos com comprometimento cognitivo e/ou demência apresentam, na maioria das vezes, com transtornos comportamentais e dependentes de cuidadores, seja familiar ou profissional, para executarem cuidados em graus variados. Essas demandas costumam gerar estresse no cuidador, aumentando a probabilidade de violência.

Muitas vezes, o simples fato de levar o alimento à boca do idoso de forma brusca; de deixar a comida para que ele próprio se alimente, sem ter condições para tal; pressioná-lo para andar mais rápido, quando este tem dificuldade de mobilidade; negligenciar sua higienização na presença das incontinências; abandoná-lo em cima de uma cama por horas, sem checar se está frio ou calor; não identificar a necessidade de tomar banho de sol; e desconsiderar a necessidade de convivência com pessoas, são as mais comuns e terríveis formas de violência contra o ser humano que envelhece em condições de baixa capacidade física e cognitiva.

Identificar a violência contra pessoas idosas é complexo e necessita de criteriosa avaliação, pois elas costumam ocultar ou não afirmar terem sofrido maus-tratos, principalmente quando advém de pessoas próximas e do meio familiar, com vínculo afetivo, ou ainda, quando o idoso possui demência em que não os permite comunicar com fidelidade os fatos ocorridos.

Dito disso, no cenário da atual epidemia da COVID-19, cujo grau de morbimortalidade se apresenta alto, principalmente estando os idosos classificados como grupo de risco e tendo uma ou mais disfuncionalidades, os cuidados necessitaram ser redobrados. Essas condições, somadas ao isolamento social obrigatório para esse grupo, apresentou-se como um dos mais importantes preditores de violência física aos idosos na epidemia $^{5}$, haja vista que os agentes de saúde ficaram impossibilitados de visitar os idosos acamados com maior frequência; o acesso aos serviços de saúde tornou-se limitado, por serem do grupo de risco e recomendados a permanecer na residência; as visitas de outros familiares foram reduzidas, criando condição ideal para que o idoso que apresenta incapacidade funcional e cognitiva sofresse as mais variadas formas de violência. 
A reflexão acerca da violência contra a pessoa idosa, decorrente da sua incapacidade funcional e cognitiva, em meio a epidemia da COVID-19, é fundamental para àqueles que cuidam, seja familiar, cuidador formal ou profissional de saúde, atentando para o monitoramento desses idosos, por meio de visitas ou teleconsultas. Para mitigar os riscos de violência durante o período da COVID-19, estratégias de apoio e orientação podem ser adotadas para que os familiares e cuidadores possam conduzir os momentos de tensão(5).

Assim, de acordo com o grau de comprometimento cognitivo e com base na avaliação da capacidade de compreender as informações, os idosos devem ser informados sobre a ocorrência da doença para que possam compreender, apesar das limitações, a adoção das medidas protetivas como a higiene das mãos, uso de máscaras, distanciamento entre as pessoas e as mudanças repentinas na sua rotina em decorrência da situação, como também a solicitação de ajuda em casos de violência ${ }^{(6)}$.

\section{CONDIÇÕES SOCIODEMOGRÁFICAS GERADORAS DE VIOLÊNCIA}

Determinadas características, tanto atribuídas ao idoso como ao seu possível agressor, aumentam as chances de ocorrência de violência. Configuram-se como fatores de risco entre os idosos: pertencer ao gênero feminino, possuir incapacidades funcionais e cognitivas, compartilhamento de residência com outros membros da família de diferentes gerações e não possuir rede de suporte social. Com relação aos agressores, são fatores de risco: pertencer ao gênero masculino, idade superior a 40 anos, vivência familiar de comportamentos abusivos, ser cônjuge/filho(a) da vítima, história de distúrbio mental e/ou de uso de álcool e drogas ${ }^{(3)}$.

Na relação da violência com o processo de envelhecimento, destacam-se as características de gênero, não somente porque as mulheres alcançam maior longevidade em relação ao homem, mas, também, devido o histórico de maior vulnerabilidade da mulher para ocorrência de violência em todas as faixas etárias, principalmente se a mulher afrodescendente. Deve-se considerar que sempre existiram normas na sociedade para regular condutas de homens e mulheres, jovens e idosos etc., determinando o que é aceitável para as mulheres, o que pode inibir o reconhecimento de seus direitos e a procura de auxílio por parte das idosas.

Importante também enfatizar as violências produzidas por choque de gerações, por disputa de espaço físico e por questões financeiras que estão envoltas em um imaginário social que ainda considera a velhice e o idoso como "peso" e como ser "descartável". Além disso, condições sociais negativas de baixa renda, baixa escolaridade, doenças crônicas e dificuldades de acesso a serviços de saúde e às informações são fatores que costumam contribuir para o aumento da violência contra a pessoa idosa. No entanto, existe um equívoco em se pensar que somente pessoas menos favorecidas economicamente e com baixa escolaridade sofrem violência. Ela está presente em todas as classes sociais.

A violência contra a pessoa idosa faz-se presente também nas instituições, quando estas estabelecem condições de coação, levando à danos físicos, mentais e morais. Ela perpassa por questões conjunturais e macroestruturais cuja responsabilidade das instâncias superiores não pode deixar de ser discutida e, na sua ausência, também se torna um fator de manutenção e perpetuação da violência.

No contexto atual, perante a epidemia da COVID-19, as pessoas idosas foram as maiores vítimas de violência das instâncias institucionais e superiores: inicialmente por terem sido os primeiros obrigados a manterem isolamento do meio social; em seguida por serem vistos como fator de dispêndio à sociedade; por não terem a prioridade dos leitos em UTl; por serem atingidos pela redução de oferta e dinâmica do atendimento nos serviços de saúde pela Estratégia de Saúde da Família; e pela mudança de logística de monitoramento e de atendimento aos idosos em condições crônicas e aos infectados pela COVID-19(7).

Na comunidade, o isolamento social e o temor de transmissão da doença levaram a situações conflitivas diante da presença de idosos em determinados ambientes externos. No individual, a ausência de familiares, levaram a saída de idosos do seio do seu lar para um novo ambiente, como mais um motivo estressor os idosos sofreram com a descompensação das doenças crônicas, déficit cognitivo, ansiedade e depressão. Todos esses fatores favorecem 
a propagação da COVID-19 no grupo de idosos, haja vista se tratar de situações que fragilizam o corpo e a mente, tornando-os mais vulneráveis à contaminação e mais expostos à violência, por demandarem de maiores cuidados $^{(7)}$.

A dificuldade de acesso às informações condizentes com a capacidade de entendimento dos idosos é um fator importante a se discutir, uma vez que na ausência delas, os idosos tendem a se submeterem às ideias, aos cuidados e às vontades de terceiros, às vezes mal-intencionados. Além disso, o idoso deixa de conhecer os serviços sociais e redes de apoio que poderiam dar-lhe maior segurança e proteção. Ao contrario também ocorreu nessa pandemia as informações excessivas e as Fake News possuem como alvo majoritários idosos, como casos de abuso financeiro e propagação de tratamentos.

Cabe ressaltar, que as atuais condições epidemiológicas e seus efeitos estão sendo vivenciados pelas famílias de forma distinta. Portanto, manter vigilância sobre a ocorrência dos casos e articular ações interdisciplinares com outros setores sociais pode contribuir para garantir proteção e segurança da pessoa idosa, bem como melhorar a prevenção e o enfrentamento deste sério problema social.

Em condições epidêmicas normais os enfermeiros que atuam na Atenção Básica dispõem de maiores oportunidades, em vista de sua proximidade com a comunidade, realizando ações destinadas a reduzir situações de risco para as pessoas idosas, familiares e pessoas de seu convívio social, promovendo atitudes positivas em relação a sua tratativa, informando o público em geral acerca dos fatores de risco geradores de maus-tratos e sobre as melhores práticas que coloquem o idoso em situações de ameaça ou perigo ${ }^{(8)}$. Porém, nesse cenário de epidemia, a responsabilidade de investigar e notificar situações de violência passa a ser maior dos enfermeiros que atuam nos serviços triagem em centro de campanha, de urgência/emergência ou nas UTIs, sendo essas a principal porta de entrada na atual circunstância.

\section{VIOLÊNCIA DOMÉSTICA DURANTE O ISOLAMENTO SOCIAL}

A família é o primeiro núcleo de socialização dos indivíduos, onde se constroem e experimentam os vínculos básicos e outorgam identidade aos sujeitos. Dependendo da forma de organização familiar, os sujeitos podem experimentar muitas situações de violência doméstica, que são omitidas, ocultadas e/ou disfarçadas por seus membros e pela sociedade. A violência, por vezes, encontra, nas relações familiares, um campo fértil, mesmo que nelas haja relações íntimas e afetivas.

A violência doméstica ou intrafamiliar é toda ação ou omissão que interfira no bem-estar, na integridade física, psicológica ou na liberdade e no direito ao desenvolvimento de outro membro da família. Pode ser praticada dentro ou fora do domicílio por um membro da família, incluindo pessoas que passam a assumir a função parental, mesmo sem laços consanguíneos e em relação de poder à outra pessoa ${ }^{(9)}$.

Estudos nacionais e internacionais ressaltam uma associação significativa da violência doméstica com o grau de dependência do idoso e o grau de parentesco, demonstrando que o principal agressor/violador dos direitos dos idosos são familiares ou pessoas próximas que convivem no domicílio com ele ${ }^{(3-5)}$. Assim, é no seio familiar que são praticadas as mais diversas formas de violência contra a pessoa idosa, sendo, quase sempre, mantida como segrego pela família, daí ela ser entendida como uma violência "velada", sofrida em silêncio.

Partindo-se do conceito de violência, podemos particularizar a violência doméstica em violência doméstica em sentido estrito, que está relacionada a prática de maus tratos físicos e psíquicos, ameaça, coação, injúrias, difamação e crimes sexuais; e violência doméstica em sentido lato, caracterizada pela violação de domicílio e/ou perturbação da vida privada, devassa da vida privada (imagens, conversas telefônicas, e-mails, revelar segredos e fatos privados, violação de correspondência), violência sexual, violação da obrigação de alimentos, homicídio (tentado/consumado), dano, furto e roubo. De modo geral, podemos dizer que a violência doméstica engloba diferentes tipos de abuso podendo surgir isoladamente e/ou combinados com as diversas formas de violência como a social, emocional, financeira, física, sexual, negligência, perseguição e abandono ${ }^{(9)}$.

Uma família pode oferecer um ambiente domiciliar saudável e harmonioso ou deixar-se contaminar pela violência, por relações tensas entre seus membros ou pessoas próximas. Dentro desse ambiente, os idosos 
normalmente se mostram indefesos em razão da idade, deficiência e/ou presença de doença, independente das suas condições sociodemográficas.

Com o distanciamento, isolamento e o confinamento social durante a pandemia da COVID-19, as demandas de cuidado em domicílio das pessoas idosas aumentaram e, consequentemente, as condições de vulnerabilidade à violência doméstica se intensificaram. Os cuidados pessoais e, principalmente, os de saúde que antes eram divididos entre a família e os serviços de saúde, passaram a ser concentrados no domicílio para reduzir o risco de contaminação, resultando em maior sobrecarga ao cuidador principal. Assim, nas residências, houve alteração da rotina das famílias, criando um clima de mais tensão, elevação do estresse e maior presença da violência doméstica.

No Brasil, entre os meses de março a maio de 2020, com os casos de COVID-19 em alta e a obrigatoriedade do isolamento social, as denúncias de violência contra a pessoa idosa aumentou cinco vezes mais, passando de aproximadamente 3 mil para quase 17 mil casos. Isso indica que o isolamento social conseguiu reduzir o número de casos de COVID-19 em idosos, no entanto, ajudou a aumentar sua exposição à violência doméstica. Para reafirmar isso, os dados divulgados de 2011 a 2018 mostram que houve um aumento médio de $20 \%$ nas denúncias dos casos de violência, enquanto que o mesmo período de 2020 registrou aumento de $400 \%$, sendo que só os registros do mês de maio de 2020 foi mais que o dobro de todas as denúncias ocorridas durante o ano $2011^{(2)}$.

A maior parte das denúncias estavam ligadas a violência financeira, psicológicas e físicas, mas, principalmente à violência financeira, uma vez que o país entrou em recessão e a única renda fixa de várias famílias era a aposentadoria do idoso. Na violência financeira sofrida pelos idosos e registradas no Disk 100 predominaram os empréstimos consignados, fraudes com cartão de crédito e sequestro da renda. As violências psicológicas e físicas, estavam relacionadas à questão do aumento da demanda de cuidados por parte dos familiares. $\mathrm{A}$ indisponibilidade de atendimento pelos serviços saúde da Rede de Atenção Básica voltados para os idosos mais dependentes desses serviços, contribuem muito para agravar o problema ${ }^{(2)}$.

Pode-se dizer que a epidemia pelo COVID -19 trouxe evidencias da necessidade de se resgatar a cidadania e os direitos dos idosos, garantidos na Constituição e no Estatuto do Idoso; e a aplicação de maiores investimentos no combate à violência contra a pessoa idosa, incluindo um programa de ajuda à família que tem um idoso dependente para ser cuidado no domicílio. Só assim poderá se vislumbrar uma redução das ocorrências de violência domiciliar.

\section{Contribuições para a enfermagem}

A enfermagem tem um papel importante na prevenção, identificação e intervenção no processo da violência contra a pessoa idosa, mas, para isso, precisa participar efetivamente da organização dos serviços, na qualidade e humanização dos cuidados, discutindo e criando estratégias de enfrentamento, atuando em programas de treinamento e sensibilização dos profissionais que atuam com idosos e seus familiares. Assim, por meio de uma atitude de respeito e sensibilidade às questões referentes a violência e maus tratos aos idosos, a Enfermagem tem responsabilidade social de apoiar, informar e incentivar sobre os serviços de proteção e acolhimento para pessoas idosas que vivenciam uma situação de vulnerabilidade física, social e psicológica que repercute diretamente na sua dignidade e existência.

\section{CONSIDERAÇÕES FINAIS}

O enfermeiro ao cuidar da pessoa idosa precisa considerar suas especificidades decorrentes do processo de envelhecimento aliados à instalação de doenças e/ou agravos que acarretam prejuízo na sua autonomia, independência e capacidade funcional. Além disso, na interação com idosos precisa saber identificar aqueles em situação de maior vulnerabilidade física, social, psicológica e econômica para o planejamento de ações que atendam as suas necessidades e, também preservem o respeito à sua dignidade, valores culturais e direitos. Nesse sentido, é fundamental que o enfermeiro conheça e avalie o contexto familiar e social em que o idoso vive e desenvolve suas 
atividades, reconhecendo precocemente indícios de violência mediante observação atenta do comportamento, gestos, semblante, entonação de voz e outras expressões não verbais da pessoa idosa para promover suporte e orientação ao idoso e família. Contudo, em tempos de pandemia pelo COVID-19, quando as pessoas idosas estão mais expostas a ocorrência de violência, é fundamental que o enfermeiro tenha uma atitude mais empática e ativa para ajudar e apoiar à pessoa idosa e sua família, haja vista que o isolamento social, o ambiente familiar e a convivência cotidiana podem contribuir para desencadear situações de conflitos geradores de violência.

\section{AGRADECIMENTO}

\section{Ao Departamento Científico de Enfermagem Gerontológica da ABEn Nacional.}

\section{REFERÊNCIAS}

1. Brasil. Secretaria de Direitos Humanos da Presidência da República. Brasil: manual de enfrentamento à violência contra a pessoa idosa. É possível prevenir. É necessário superar. / Secretaria de Direitos Humanos da Presidência da República; Texto de Maria Cecília de Souza Minayo. Brasília, DF: Secretaria de Direitos Humanos da Presidência da República, 2013.[Internet]. 2020 [cited 2020 Jun 02]; Available from: http://www.cedi.pr.gov.br/arquivos/File/CEDI/ManualViolencialdosogovfedweb.pdf

2. Brasil. Ministério da Mulher, da Família e dos Direitos Humanos - DISQUE 100. Balanço anual do Disque 100 registra aumento de 13\% em denúncias de violações contra a pessoa idosa. Brasília: Ministério da Mulher, da Família e dos Direitos Humanos2019[Internet]. 2020[cited 2020 Jun 05]; Available from: https://www.gov.br/mdh/pt-br/assuntos/noticias/2019/ junho/balanco-anual-do-disque-100-registra-aumento-de-13-em-denuncias-de-violacoes-contra-a-pessoa-idosa.

3. Castro VC, Rissardo LK, Carreira L. Violence against the Brazilian elderlies: an analysis of hospitalizations. Rev Bras Enferm [Internet]. 2018. [cited 2020 Jun 10];71 (suppl 2):777-85. [Thematic Issue: Health of the Elderly]. Available from: https:// www.scielo.br/pdf/reben/v71s2/0034-7167-reben-71-s2-0777.pdf

4. Faustino AM, Moura LBA, Gandolfi L. Relationship between violence and cognitive function in the elderly. Rev enferm UFPE on line [Internet]. 2016 [cited 2020 Jun 12];10(5):1717-23. Available from: https://periodicos.ufpe.br/revistas/ revistaenfermagem/ article/viewFile/13547/16321

5. Han SD, MosquedaL. Elder abuse in the COVID-19 Era. J Am Geriatr Soc. line [Internet]. 2020 [cited 2020 Jun 10];00:12. Available from: https://onlinelibrary.wiley.com/ doi/epdf/10.1111/jgs.16496

6. Brasil. Ministério da Saúde. Fundação Oswaldo Cruz (Fiocruz). Saúde Mental e Atenção Psicossocial na Pandemia de COVID-19. Violência Doméstica e familiar na COVID-19. 2020. [Internet]. 2020 [cited 2020 Jun 13]; Available from: https:// portal.fiocruz.br/sites/ portal.fiocruz.br/files/documentos/saude-mental-e-atencao-psicossocial-na-pandemia-covid-19violencia-domestica-e-familiar-na-covid-19.pdf

7. Brasil. Ministério da Saúde. Painel de casos de doença pelo coronavírus 2019 (COVID-19). [Internet]. 2020 [cited 2020 Jun 12]. Available from: https://covid.saude.gov.br/. Acesso em: 14 de junho de 2020.

8. Souza CRS, Reis DA; Castro FF, Carreira L, Nascimento V. Prevenção da covid-19 na população idosa indígena. In: Enfermagem gerontológica no cuidado do idoso em tempos da COVID 19. Associação Brasileira de Enfermagem. Brasília, DF: ABen/DCEG. [Internet]. 2020. 2012 [cited 2020 Jun 18].74 p. (Série enfermagem e pandemias). Available from: http:// www.abennacional.org.br/site/wp-content/uploads/2020/05/E-BOOK-GERONTO.pdf

9. BRASIL. Ministério da Saúde. Violência intrafamiliar: orientações para prática em serviço. Cadernos de Atenção Básica n.8. Secretaria de Políticas de Saúde. Brasília: Ministério da Saúde, 2002. [Internet]. 2020 [cited 2020 Jun 15]; Available from: http://bvsms.saude.gov.br/bvs/publicacoes/violencia_intrafamiliar_cab8.pdf 